\title{
Usos e abusos da leitura de Proust: reflexões em torno de Como Proust pode mudar sua vida (Alain de Botton) e Proust e os signos (Gilles Deleuze)
}

\section{Uses and abuses of Proust reading: reflections on how Proust can change your life (Alain de Botton) and Proust and the signs (Gilles Deleuze)}

leda Tucherman ${ }^{1}$ | Universidade Federal do Rio de Janeiro Doutora e Comunicação e Cultura com pós-doutorado no IRCAM, Georges Pompidou, Paris. Professora do Programa de Pesquisa e pós-graduação da Escola de Comunicação da Universidade Federal do Rio de Janeiro, bolsista pesquisadora do CNPq e coordenadora do grupo de pesquisa Imaginário Tecnológico.

\section{Resumo}

A proposta deste texto é antiga, tratando de uma indagação que retorna por meios contemporâneos: a arte deve ser medida ou produzida com um sentido de utilidade? Sem julgamento a priori, as duas propostas das leituras que apresentamos se relacionam de maneira contrastante com esta inquietação: a leitura de Alan de Botton é quase terapêutica; Proust, um dos mais herméticos escritores do século XX, aparece a partir de rubricas que podemos associar aos títulos da literatura de autoajuda. Em Deleuze, ela reside no fato de ser a literatura a experiência de gaguejar na própria língua, produzir mundos possíveis no campo da arte e dos sistemas de pensamento. Neste caso, ao contrário de acalmar ou indicar caminhos, sua função é nos lançar na zona do inesperado.

Palavras-Chave: Arte, terapêutica, autoajuda.

\section{Abstract}

The proposal of this text is old, dealing with an inquiry that returns by contemporary means: should art includes a sense of utility? Without an a priori judgment, the two proposals of the readings that we present shows those two very different ways of approaching Proust's literature: the reading of Alan de Botton is almost therapeutic; Proust, one of the most hermetic writers of the twentieth century, appears from rubrics that we can associate with the titles of the self-help literature. In Deleuze, it lies in the fact that literature is the experience of stuttering in one's own language, producing possible worlds in the field of art and systems of thought. In this case, as opposed to calming or indicating paths, its function is to throw us into the zone of the unexpected.

Keywords: Art, therapeutic, self-help. 
"Os deuses esqueceram o que faz viverem os homens".

\section{Introdução}

De um ponto de vista imediato, basta dizer que aquilo que pensamos serem direitos inteiramente vinculado à subjetividade, liberdade, felicidade e saúde são uma demanda recente na história humana. Para alguns historiadores das ideias como Anne Marie Moulin², a Modernidade, incluindo a primeira 1/2 do século XX teve três palavras chave:

1- Século XVIII- liberdade

2- Século XIX-felicidade

3-Século XX-saúde

Claro que as 3 ideias frequentam os 3 séculos, mas em cada momento, uma delas tem prioridade hierárquica. Hoje a ideia de saúde foi muito mais longe, ao mesmo tempo que, numa cultura de narcisismo, como quer Cristopher Lash, a ideia de felicidade se associe a de saúde como bem estar, sucesso e autoestima. E me parece que esta pode ser uma chave de leitura para o texto de Alan de Botton, criador da School of life.

Para tentar ser mais clara vale recorrer a alguns preâmbulos filosóficos: o que é a filosofia, uma certa filosofia e como ela se relaciona com a arte?

Nossa escolha para este passo apontou para a obra de Alain Badiou exposta no seu livro Por uma nova teoria do sujeito ${ }^{3}$ :a filosofia é uma revolta lógica. Revolta porque não se contenta nem com o mundo nem com as teorias sobre ele, especialmente as que apontam para a realidade atribuindo-lhe a naturalidade da evidência e não a presença de conflitos, e contra aquele que náo sabe pensar contra si mesmo. A função crítica da filosofia é uma revolta no pensamento.

Lógica porque há um desejo na filosofia e este não é o delírio ou devaneio, mas exige conceitos e rigor nesta revolta. Como revolta corresponde a uma violência, como lógica precisa preservar o desejo de uma razão mas também constituir-se como um pensamento do que é, do que surge o que é "aposta e risco".

Nosso segundo convidado para esta conversa virtual é Deleuze Para este, a filosofia nasceu com o luto do sábio, que tudo sabia, substituído pelo pretendente ou seja, o filósofo é amigo e amante do saber que não possui. Ele é um pretendente que frequenta tanto próximo quanto é possível esta terra do pensamento. No entanto, e aí é fundamental, desde o enunciado de Platão, passando pelo motivo da revolta de Badiou, e pela concepçáo de Deleuze, nós não costumarmos pensar: corriqueiramente nos limitamos a conhecer e reconhecer. $\mathrm{O}$ pensamento só surge provocado por uma violência, produto de um encontro onde não cabe a recognição, o que força o pensamento a pensar.

Além disto, e pensando na relação com a lógica, que aparece na definição de Badiou que inclui a ideia de rigor, Deleuze descreve a tarefa da filosofia como a de produzir conceitos que são como personagens no campo de imanência que ela, filosofia, constrói para acolhê-los. São os planos deleuzianos. Os habitantes 
deste plano são os conceitos. Por outro lado, os conceitos são endoconsistentes, ou seja, tem uma consistência interna, no plano da própria filosofia, mas também tem uma abertura (exoconsistentes) para outros campos do pensamento, especialmente a arte e a ciência. E vice-versa. De diferentes maneiras quando vista pela filosofia a arte existe para perturbar, para violentar, para produzir uma necessária saída da zona de conforto. A arte não apazigua. Ao contrário.

Vale contar uma historinha simpática que apareceu numa entrevista de Paul Virilio que, quando perguntado o que o fizera pensar a incerteza do real, o princípio que lhe valeu um Prêmio Nobel ele respondeu que foram dois encontros: o primeiro com o conto de Borges, O jardim dos caminhos que se bifurcam e o estudo que, mesmo sendo católico ortodoxo ele fazia do Talmud, o livro das tradiçóes judaicas. Do Talmud ele escolheu a seguinte pérola: "E Deus, na vigésima sétima teoria de criar o mundo disse: tomara que esta dê certo"

\section{A filosofia pensa a arte}

Vejamos agora como a filosofia pensa a arte, novamente recorrendo aos nossos interlocutores e aliados nesta proposta de pôr em questão o valor da utilidade para a sua compreensão e seus pressupostos.

Começando com Badiou: uma obra de arte é infinita pelas múltiplas apreensôes que propóe (Dom Quixote e as inúmeras interpretaçôes desde 1610, ano da sua publicação) mas é também o que há de mais finito: ela aparece como materialidade finita no espaço e no tempo. Como exemplo temos: $\grave{A}$ La Recherche du temps perdu (Em busca do tempo perdido), escrito na referência à França, início do século XX, especialmente nos movimentos de duas classes sociais : os Guermantes representando a aristocracia e os Verdurin a burguesia endinheirada.

Aliás a arte é finita também num outro sentido: todo artista define o fim da sua obra: vem com a palavrinha fim na literatura, na última pincelada do pintor, no último acorde de uma sinfonia. A célebre referência que se faz a Michelangelo é a de ter, depois de finalizado seu David, pedido que ele falasse. Isto demonstra a consciência, às vezes obnubilada que o artista tem da sua própria obra, o que o faz ir além do que a obra pedia e estraga-la.

O que Badiou sustenta é que a obra-de-arte é a criação da finitude a partir da multiplicidade infinita. Assim, sendo finita, a arte se inscreve num processo histórico próprio que coteja a História mas não lhe replica. Para ele existem configuraçôes que começam com um evento, que é sempre uma ruptura, e é habitada por obras que são os pontos sujeito de tal configuração.

Por exemplo, no que nos interessa, a literatura, Badiou desenha que a configuração romance se dá entre o acontecimento Dom Quixote e os acontecimentos Joyce, levando a linguagem ao seu maior limite, e Proust, na sua expansão gigantesca com o jogo de percepçóes e sensaçóes. ${ }^{4}$ Não significa que náo se escrevam mais romances, mas que um evento de ruptura já atingiu sua configuração. Este evento de ruptura aparece via uma nova concepção de subjetividade, o efeito das obras de Joyce e Proust e, sobretudo o desejo de real que caracterizou o século XX. Durante um tempo expressivo 
e ainda hoje, as biografias fazem mais sucesso editorial do que os romances, lê-se sobre o autor sem ter lido seus textos, muitas vezes.

Acreditamos que desenhar o caminho que gerou Dom Quixote demonstra os dois lados desta moeda, o finito e o infinito, mas isto vai nos obrigará a fazer uma pequena viagem no tempo, que será panorâmica, já que, de outra forma seria, a viagem em si, um outro texto.

Vamos pois pensar o acontecimento que deu a condição de possibilidade do surgimento do romance. Se quiséssemos pura brevidade, diríamos que foi a laicização do mundo. Contudo podemos desenvolver um pouco mais, mostrando as influências que os campos de pensamento produzem uns sobre os outros. A rigor, o acontecimento que fundou a ciência moderna, por tabela, gerou o romance.

Galileu é como nomeamos este acontecimento no século XVI. Seu enunciado "olho para o céu e vejo uma equação onde todos veem estrelas "aponta para a sua ideia principal, ou seja, que é a matemática que pode descrever o mundo, expulsando toda a teologia desta tarefa. Ele o fez em dois passos: no primeiro rompeu com um princípio que até então era incontestável, o IPSUM VERUM FACTUM, que afirmava que só quem cria, no caso Deus, conhece as causas e a verdade das presenças das coisas no mundo, o que funcionava como um limite intransponível.

Ora, quando se vê uma equação no céu estrelado, as estrelas podem ser de Deus, mas as equaçóes, a matemática são criações humanas, portanto o tal limite deixa de ter função. Não foi por heresia que ele foi perseguido e sim porque, retirando o solo do saber do campo do poder da Igreja, ele libertou o pensamento na direção de sua autonomia.

Coube a ele outro abalo sísmico nas condições de saber-poder vigentes até então apresentado simplesmente com uma palavra, infinito. Se o mundo tem um movimento infinito, este contradiz completamente a ideia de centro. $\mathrm{O}$ monge Giordano Bruno tirou as conclusóes revolucionárias que este projeto na ciência trazia para o campo da filosofia e do humano: "Se o universo é infinito ele não tem nem centro nem margens... assim o homem é o que tudo pode mas nada é".

É exatamente este deslocar da determinação para a liberdade que gera o que conhecemos como subjetividade: uma posição reflexiva, um conceito de costura que veio cerzir a separação ontológica dos deuses e dos homens. Tratase então de um homem ex-cêntrico que vai começar a pensar sobre sua própria vida, uma vez que não havendo mais centro, Deus não podendo ocupar este lugar inexistente, caberá ao homem construir, num processo permanente de escolha e decisão, tanto a sua vida concreta e seus vínculos sociais, como a sua vida imaginária. Assim nasce o romance, uma história fabulada sobre uma vida inexistente, que, marcada pela vivência de Cervantes da pequena fidalguia rural espanhola, inventava um modelo de subjetividade: usamos quixotesco para falar de desejos e pessoas sem limite de realidade.

Assim, os romances revelam também duas faces: a liberdade da invenção, do delírio e do devaneio e o constrangimento que a língua gera, com regras 
gramaticais e sintáticas que, podendo ser retorcidas correm o risco de afastar o leitor de sua compreensão. Escrever como diz Deleuze, é um dom de estilo.

Deleuze como antecipamos de certa forma, tem como seu interesse o estabelecer as ligaçôes entre as formas diferentes de pensamento, cabendo ao filósofo transformá-las em questôes e delas se apropriar. Na verdade, a tarefa da filosofia é produzir conceitos e os planos onde estes habitam como personagens.

\section{Proust e os signos:}

O livro Proust e os signos para Deleuze funciona para combater a filosofia da identidade e da representaçáo em nome da sua filosofia de diferença e repetição. É assim que ele nos apresenta este mundo de Proust como um sistema plural, composto de diferentes tipos de signos, indo dos mais simples aos mais complexos.

São estes os signos mundanos (e conceito de esnobismo); os signos do amor e os conceitos relativos ao afeto, especialmente, a beleza, angústia, ciúme e duração (outra influência de Bergson) os signos sensíveis e o conceito, influência de Bergson, da memória involuntária, os signos da arte, este último sendo o que acolhe todos os outros. É por isto que, contra todos que falam da $\grave{A}$ la Recherche como uma catedral, Deleuze fala do narrador como uma aranha que prende nas suas teias todos os outros. Para Deleuze a arte produz mundos possíveis, diferentes deste que habitamos; vivem na virtualidade e nada mais lógico do que pensar isto da obra de Proust, um micro mundo especial que emite signos que a filosofia deve ajudar a decodificar.

Não se diferencia neste caso também da postura de Pierce para quem o mundo é uma profusáo de signos, que alguns chamam de multiplicidade. Para Deleuze, viver é aprender a decodificar signos e esta não é uma tarefa cognitiva ou escolar, envolve a relação entre esta decodificação que seria um tipo de percepção, funcionando como na filosofia de Bergson onde a percepção está nas coisas e cuja tarefa é vital. Percebemos para viver.

No caso do tempo, Proust é a demonstração viva da sua não linearidade: o passado e o presente convivem na nossa experiência embora numa tentativa de controlar tenhamos a tendência de espacializar o tempo, e para conhecer linearizamos o tempo, passado- presente-futuro numa compreensão que gerou tanto o mito do progresso quanto um raciocínio montado em cima de determinaçóes de causas e efeitos. Deleuze aponta desde sempre a importância ética e estética de combater esta ilusão. Um dos exemplos maravilhosos que ele nos apresenta é a história de Joe Bousquet, um maratonista que levou um tiro na coluna no último dia da Primeira Guerra Mundial. Ele responde a esta tragédia de um modo muito próximo do comportamento estóico: por um lado leva o ritmo das passadas para os das frases e das letras, por outro afirma "Minha ferida existia antes de mim, nasci para encarná-la ".

Para Deleuze a $A$ la Recherche é uma experiência onde os signos formam sua multiplicidade e sua unidade. E pensar como viver é aprender a ler os signos. Trata-se de uma alfabetização que engloba a sensibilidade e os sentidos; os signos 
pertencem ao campo do olfato, do paladar, da audição e da visão, do tato. Se nos restringirmos à pura cognição não teremos nenhuma chance de decodificar ou entender os signos e os conjuntos que formam.

\section{Decantando estes mundos:}

O primeiro mundo é da mundaneidade: não existe nenhum mundo que emita tantos signos em espaços tão reduzidos e em tão grande quantidade. Estes se diferenciam segundo "famílias espirituais". Neste sentido o esnobismo é empregar os signos da sua família, os mais sutis, que raramente são percebidos pelos outros: o castão da bengala e o jeito de segurá-la, o livro de cabeceira, a mobília e mesmo a voz, o movimento e as construçóes verbais. $\mathrm{O}$ esnobismo nasce desta certeza que é impossível para quem não pertence a esta família compreender o seu mundo sígnico.

Os signos do amor fazem outro círculo: apaixonar-se é individualizar o outro pelos signos- o ser amado aparece como um signo, uma alma que exprime um mundo difícil desconhecido por nós. $\mathrm{O}$ amado corresponde a um mundo que precisamos decifrar. Também se trata de uma pluralidade de mundos: o pluralismo do amor não diz respeito apenas à multiplicidade de seres amados mas dos mundos contidos em cada um deles, Amar é tentar explicar os mundos desconhecidos que estáo envolvidos no ser amado.

Mas há uma contradição no amor: estes mundos se formaram sem nós e portanto são mundos que nos excluem. A contradição no amor deriva disto: o ciúme vira uma espécie de lei que ganha autonomia em relação ao nosso amor.

Para Proust, subjetivamente, o ciúme é mais profundo que o amor, ele contém a verdade do amor. Os signos amorosos aparecem para Proust como sendo mentirosos porque só podem dirigir-se a nós escondendo o que exprimem: a origem de um mundo, açóes e pensamentos desconhecidos, o que produz um aprofundamento no sofrimento: nunca ter por completo o ser amado. E, caso venhamos a decifrar seus mistérios deixamos de amá-lo. Só amamos em sofrimento e ciúme.

O terceiro mundo é o dos signos sensíveis ou das impressóes. Uma qualidade sensível nos proporciona uma estranha alegria, mas introduz um imperativo. Temos que descobrir o sentido que ele insinua. Finalmente o sentido do signo aparece, revelando-nos o objeto oculto, Combray para a Madeleine é o mais límpido exemplo.

Mas Combray não ressurge como esteve presente, simples associação de ideia. Dito pelo próprio Proust" o gosto da Madeleine lembrava-me Combray. Mas porque me tinham, num como outro momento, comunicado as imagens de Combray $e$ de Veneza numa alegria semelhante à certeza para, sem mais provas, tornar-me indiferente à ideia de morte".

Assim, no fim da $\grave{A}$ la Recherche o intérprete compreende o que lhe escapara no caso da Madeleine e em outros. É preciso ultrapassar este sentido material - o que está se apresentando é o mundo da arte, o que acolhe todos os signos dando-lhes um sentido estético e penetrando no que ainda tem de opaco. 
Sabemos que Proust foi, ele mesmo, um personagem torturado. Homossexual não assumido, mimado pela mãe, e torturado pela necessidade da escrita que ele definia dizendo que o talento não era escolher um tema fulgurante, era o tratamento que este recebia da escrita. Ou seja a linguagem. Para quem tem talento a leitura de uma bula vira um texto brilhante; para quem não tem, a Vênus de Milo vira uma descrição de recognição, era uma das boutades de Proust.

Para ele, que sabia do seu talento e foi rejeitado pelos editores, esta rejeição calou muito fundo. A primeira ediçáo dos primeiros livros ele teve que pagar do seu próprio bolso, o que náo o castigou financeiramente, mas pela humilhação. Vale lembrar que André Gide era parecerista de uma editora, acho que a Gallimard. E achou o livro ruim, impossível de ser compreendido e vendido. Mais tarde, como para penitenciar-se foi quem traduziu o texto para o inglês, usando como título um verso de Shakespeare, "Remembering Things past".

\section{Alan de Botton e a lógica contemporânea}

Diferentemente de muitas pessoas não acho que o livro Como Proust pode mudar sua vida convide o leitor a ler $\grave{A}$ la Recherche; nem acho que este teria sido o objetivo do autor, Alan de Botton. Esta foi a opinião de algumas pessoas que com este argumento elogiavam o livro do autor. A rigor o livro, que é simpático e menos prescritivo que a tradiçáo anterior dos livros de autoajuda, definiu a carreira de Alan de Botton: este escreveu seu primeiro livro, Ensaios de Amor, em 1993. Publicou outros entre 1993 e 1997, mas o texto que realmente alavancou sua carreira foi exatamente Como Proust pode mudar sua vida de 1997.

A motivação do escritor Alan de Botton nos parece bastante nobre, pois que, individualmente, participamos do seu ponto-de-vista, a saber, que a religião não explica nada, depende da fé que é, em si mesma e por definição, acrítica. Neste sentido ele propóe substituir a religiáo pela filosofia, movimento que o fez fundar a School of life, com sede central em Londres e braços espalhados pelo mundo, no Brasil inclusive, cujo princípio é o de educar para a vida real, envolvendo depurar uma inteligência emocional e uma habilidade de escolha que permita viver uma vida melhor ${ }^{6}$.

Por outro lado, como seu objetivo é o de educar o maior número de pessoas e ser acessível a todos, ele "barateia" sua filosofia e acaba fornecendo "liçôes" que têm uma visada interventora, prescritiva. "Eu ensino o que deve ser feito e como fazê-lo", "seguir este programa torna a chance de viver bem muito provável”. Não há quem goste de pensar que acredite em soluçôes universais, esta seria nossa primeira e principal crítica.

Voltando à ideia de que não achamos que a leitura de Como Proust pode mudar sua vida encaminhe o leitor em direção à obra de Proust pensamos, ao contrário, que o livro conduz de maneira muito sofisticada a um movimento recente onde a felicidade é concebida (no imaginário) tanto popular quanto o científico como um projeto de reengenharia individual, orientado por um conjunto de especialistas que tratam da reprogramação da mente, do cérebro ou da mudança de aparência e de postura. Temos muitos experts (também 
chamados de coachers) que indicam e acompanham seus clientes na busca do bem estar subjetivo, ou da potencialização da performance. Vale lembrar que estas figuras e seus produtos são contemporâneos também de outra "bengala", aquela que diagnostica os aparentes sintomas de não felicidade, tristeza, spleen e propóe remédios que liberando os hormônios necessários tais como noradrenalina e serotonina devolvem o gosto de viver.

Como diz Ehrenberg: Marx disse que a religião é o ópio do povo, mas o que temos hoje é uma sociedade dopada. Aí enquadramos tanto os fármacos quanto as técnicas de autoajuda, já que ambas agem da exterioridade para a interioridade subjetiva.

Para ficar mais organizado vale um parêntese político e histórico baseado em duas citações de Foucault, muito próximas no tempo, que funcionam como premissa para a nossa análise. A primeira aparece nas páginas finais da Vontade de Saber, primeiro volume da História da Sexualidade: "O homem durante milênios permaneceu o que era para Aristóteles: um animal vivo e, além disso, capaz de existência politica; o homem moderno é um animal em cuja política, sua vida de ser vivo está em questão" (Foucault,1976/ 1984, p134).

A segunda no Nascimento da biopolitica, curso no Collège de France, 1978-1979 (2008), Foucault acrescenta um dado fundamental para entendermos o nosso hoje, quando anuncia que o homem econômico seria substituído pelo empreendedor de si mesmo, tornando-se um capital humano constituído de elementos que seriam inatos e outros fatores adquiridos.

Não admira o surgimento do interesse pela genética que corresponde aos valores inatos e nos apresentou algumas figuras estranhas: o portador (o presente existe para combater o futuro provável) e a ideia de tendências ou suscetibilidades. Em alguns autores vira mesmo determinismo biológico, totalmente o avesso das conquistas da modernidade: liberdade no lugar de determinação e responsabilidade. Aí a biologia é destino.

Se pensarmos em valores adquiridos, somos constantemente apresentados a promessas que falam da conquista de uma longevidade inimaginável, ou, se levarmos os mais eufóricos em consideração, na erradicação da morte natural. Mais do que isto e de um significado a nosso ver mais insidioso, na chamada sociedade tecnológica de informação, estamos numa espécie de nome fantasia que designa no plano da vida a entrada num século governado pela biopolítica.

Podemos apontar que neste momento a biopolítica, que significa administração da vida, funciona como uma colonização tanto da vida como do imaginário. Temos atualmente um desenho que indica, entre as ciências atuais, um prestígio radical das ciências da vida assim como das biotecnologias. Os motivos para tal têm origens variadas, contudo podemos apontar os três principais: a aliança da ciência com a empresa o que explica a presença monumental nos fármacos e na banalização dos diagnósticos; o projeto Genoma, o mais caro já realizado, com suas promessas, a primeira sendo a de erradicação das doenças, problemática que concerne a um projeto de reengenharia da vida e, finalmente, os dispositivos de visibilidade que tornaram visíveis todos os 
rincôes do nosso corpo , incluindo do nosso cérebro. Até mesmo a afirmação orgulhosa de Merleau-Ponty de que nunca veremos um cérebro pensando tornou-se obsoleta diante dos novos exames, pet-scans e ressonâncias magnéticas. Tornar visível produz o efeito de uma evidência, ligada etimologicamente ao ver, e esta, por sua vez, parece representar um fundo indiscutível de verdade

Então temos um desenho bipartido do futuro: o primeiro aposta que a nova geração de psicofármacos poderá, em curto prazo de tempo, nos permitir intervir na nossa subjetividade mais imediata, atuando de maneira a equilibrar nossos desejos, nossos humores, emoções, desejos e inteligência.

O segundo movimento consiste numa nova prática ou um acentuado deslocamento das relaçóes e práticas de interpretação e aconselhamento, de consolo ou de motivação, para outras formas de comunicação, em tudo consistentes tanto com a cultura de massa quanto com os nichos de customização que identificamos nela.

Significa dizer que se tornou visível um distanciamento do consagrado campo das ciências psi, especialmente da psicanálise que havia reinado nas décadas de 1960 a 1980, por outros modelos, mais rápidos, eficientes e pragmáticos. Estes podem ser pensados como comunicantes, mesmo que em teoria sejam bastante distintos: as neurociências e o interesse pelo cérebro onde estariam disponíveis todas as informaçóes sobre o que é humano e a autoajuda, nosso tema de escolha.

Então, a primeira reflexão que podemos apresentar sobre o surgimento e a expansão da literatura de autoajuda comprova que os temas, situaçóes e comportamentos, afetos e angústias, que já foram o lócus de atuação das religiōes, da psicologia, e de outras ciências sociais e comportamentais, migraram para um domínio que, embora tenha um nascimento longínquo (já que o primeiro texto explícito seria de 1859), é na nossa atualidade o que se transforma neste êxito de massa: a autoajuda. Nesta medida acreditamos que o campo a autoajuda se insere totalmente na lógica do biopoder.

Para não ser injusta, mesmo sendo um pouco leviana, o campo da psicologia que nasceu e se desenvolveu foi o da psicologia positiva, que tem muitas similaridades com a autoajuda. De forma muito abreviada, a psicologia positiva funciona a partir da hipótese de um déficit de conhecimento: não percebemos direito as situaçóes e por isto erramos na nossa ação. Precisamos de ajuda para compreende-las e agir de acordo.

\section{Como Proust pode mudar sua vida: Alan de Botton}

Para mim Alan de Botton de uma maneira muito sofisticada, com uma erudição do filósofo (que é a sua formação acadêmica) atua com sua vasta obra neste mundo que Bauman chamou, em "Vida para Consumo", o do surto do aconselhamento, mesmo que este livro não seja autoajuda em estado bruto, ou seja não é autoajuda na veia.

Duas características imediatas aproximam Como Proust pode salvar sua vida dos textos de autoajuda: o próprio título que se aproxima dos muitos títulos que abrem com um Como nas obras de autoajuda, tais Como fazer amigos 
e influenciar pessoas ${ }^{7}$, e a forma de organização do livro: capítulos curtos e com conclusóes apontadas no final de cada um deles. Não consigo deixar de pensar que há uma esperteza criativa que confere muito prestígio à aliança ao nome de Proust, mas por outro lado, um uso deste totalmente diferente, senão oposto, ao que o próprio Proust desejaria.

Usando palavras do próprio de Botton, tal como ele fez com Proust, creio que conseguiremos provar nosso ponto-de-vista. Eis o primeiro texto, selecionado entre exemplos arbitrariamente escolhidos:

Do primeiro capítulo (Como ler para si mesmo):

Ao lermos a obra-prima de um homem brilhante, ficamos felizes em descobrir que reflexóes nossas, que haviamos desprezado, alegrias e tristezas que haviamos reprimido, todo um mundo de sentimentos que haviamos desdenhado e cujo valor nos é repentinamente ensinado por este livro (...).(pg. 32)

Usando um texto de Proust, sem indicar qual seja, de Botton reforça o seu pensamento em torno de uma literatura educativa e, em certo sentido, utilitária. O segundo capítulo já apresenta, no próprio título, a indicação prescritiva: Como não se apressar (pg. 42 a pg.64), e também apresenta o que seria um conselho proustiano "N’allez pas trop vite" (não vá muito rápido).

O terceiro capítulo tem um título delicioso: Como sofrer com sucesso: "Sofremos porque pensamos e o fazemos porque o pensamento nos ajuda a contextualizar a dor, a entender sua origem, a medir suas dimensóes e nos reconciliar com a sua presença" (pg. 58) e, logo em seguida, "Há dois métodos para que uma pessoa adquira alguma sabedoria - sem dor, por meio de um professor, ou com dor, por meio da vida -e propóe que a variante com dor é muito superior" (pg. 59). Por outro lado, citando o próprio Proust, "uma mulher de quem não podemos prescindir nos faz sofrer, arranca-nos, como não faria nenhum homem superior que nos interessasse, toda uma gama de sentimentos profundos, vitais (pg. 90) ${ }^{8}$. Este capítulo é longo (pg. 66 à pg. 111), e nele esta presença educacional é muito acentuada, como se torna mais claro no comentário de Botton a respeito dos humores de Madame Verdurin: "Uma solução melhor : porque sempre queremos mais do que temos e porque sempre há mais pessoas que não nos convidam do que as que convidam " (pg. 97).

Os títulos dos capítulos seguintes são: Como expressar suas emoçôes; Como ser um bom amigo; Como Abrir os olhos; Como ser feliz no amor; Como abandonar os livros. É muito fácil achar exemplos do argumento que propomos em todos eles, sobretudo porque o Como tem uma indicação de exemplo e/ou de indicação de caminho. O único momento em que isto é nuançado é quando de Botton, fazendo uma referência expressa ao comentário de Proust sobre Ruskin apresenta o que ele, de Botton, chama de A moral: " Transformar (a leitura) em disciplina é atribuir um papel grande demais ao que é apenas um incentivo. Ler está no limiar da vida espiritual e pode apresentá-la a nós, mas não a constitui “(pg. 251)

Claro deve estar que esta é uma leitura que fizemos. Mas se pensarmos que o criador da autoajuda, Samuel Smiles, no livro Self-Help, 1859 usa como referência a autobiografia de Benjamin Franklin, porque seria um exemplo 
edificante, Alan de Botton usa Proust e A La Recherche também nos apresentando comportamentos mais ou menos bem sucedidos. Náo é a mesma coisa, mas particularmente me parece cotejar o surto de aconselhamento onde o guia é ora o livro, ora o autor.

Essa configuração nos permite ponderar que, entrando neste universo, parece-nos possível pensar que três fenômenos culturais mais recentes articulam-se neste dispositivo, a saber: o atual e incontestável sucesso dos produtos culturais da autoajuda, começando pelo seu sucesso editorial; a moda das biografias que partilham uma fatia nada insignificante deste mundo livresco e o prestígio do testemunho, proposto em primeiro lugar pela antropologia cultural e pela história das mentalidades, que podemos compreender como uma herança laica e transformada da prática do confessionário (aí incluindo-se a busca e o desejo de um pastor que oriente o percurso, seja este vivo e próximo, ou surja a partir de uma narrativa biográfica). Este prestígio do testemunho, ainda que do texto é curioso.

Nos nossos estudos, os produtos que se apresentam diretamente como sendo de autoajuda, vemos a constância de um modelo: começa com a figura de um depoimento - alguém narra seus problemas, as injustiças de que padece, enfim, é a vitimização; o segundo passo é o envolvimento, a persistência, o esforço; e finalmente temos o testemunho, que mostra o efeito positivo do tratamento a partir do depoimento (é como se estabeleceu o modelo dos alcóolatras anônimos).

Por outro lado, a grande diferença que aparece no texto de Alan de Botton é que este parece sugerir uma busca de competência, enquanto que a acelerada autoajuda contemporânea fala a partir da eficácia. Este seria o ponto onde ele parece se afinar mais com nosso princípios da modernidade.

Curiosamente, de Botton fundou e/ou participa de um conjunto editorial no qual encontramos títulos como Nietzsche para estressados: noventa e nove liçôes para despertar a mente e combater as preocupaçôes; Kafka para sobrecarregados; Einstein para distraídos, Shakespeare para apaixonados; Oscar Wilde para inquietos, todos estes escritos por Allan Percy. Com colagens de fragmentos dos textos dos autores referenciados nos títulos respectivos, mais do que celebrados no conjunto, a edição que Percy realiza nos textos esvazia todos os autores convocados daquilo que os consagrou como únicos, e os embrulha na tarefa de consolo e indicação de comportamento, ao contrário de uma abertura para o pensamento. Neste sentido, Alan de Botton é muito menos atuante: seu convite é para pensarmos (melhor) e, a partir daí moldarmos nosso comportamento. Acreditamos que pode ser nossa tarefa defender os autores contra uma simplificação objetivante.

\section{Referências bibliográficas}

BADIOU, A, Para uma nova teoria de sujeito, RJ. Relume-Dumará, 1994

BADIOU, A. O Século. Aparecida, Editora Ideias e Letras, 2007.

BAUMAN, Z. Vida para consumo. RJ, Jorge Zahar Editora, 2007. 
DE BOTTON. Como Proust pode salvar sua vida. RJ, Intrínseca, 2011.

DELEUZE, G. Proust e os signos. RJ, Editora Forense Universitária, 2006.

DELEUZE, G. e GUATTARI, F. O que é a filosofia? São Paulo, Editora 34, 1991.

EHRENBERG, A. La fatigue d'être soi. Paris, Odile Jacob. 2000.

FOUCAULT, M. A vontade de saber. In História da Sexualidade. vol.I, RJ, Graal, 1980. Nascimento da biopolítica. São Paulo, Martins Fontes, 2008.

MOULIN, A. M. O corpo diante da medicina In História do corpo. vol I,pg 15 a 82. Petrópolis, Editora Vozes, 2008.

TUCHERMAN, I. Autoajuda, midia e biopoder. Porto Alegre, revista Famecos, PUC-RS, 2012

- Subjetividade contemporânea numa sociedade biotecnológica de mercado. Niterói, Revista Ciberlegenda, UFF, 2015.

\section{Notas}

1. Doutora e Comunicação e Cultura com pós-doutorado no IRCAM, Georges Pompidou, Paris. Professora do Programa de Pesquisa e pós-graduação da Escola de Comunicação da Universidade Federal do Rio de Janeiro, bolsista pesquisadora do CNPq e coordenadora do grupo de pesquisa Imaginário Tecnológico.

2. Anne Marie Moulin, História do Corpo, Volume III, Petrópolis, Editora Vozes

3. BADIOU, Rio de Janeiro, Relume Dumará, 1994

4. Proust conhecia a obra de Bergson que lhe foi muito útil para pensar o jogo entre matéria e memória e entre memória voluntária e involuntária.

5. Deleuze, Lógica dos Sentidos.

6. http://www.theschooloflife.com/saopaulo/. Acesso em 17 de fevereiro de 2017.

7. "Como fazer amigos e influenciar pessoas", de Dale Carnegie. Originalmente publicada em 1936, segundo informaçóes no site da livraria Saraiva, "em sua 51º edição, com mais de 30 milhóes de exemplares vendidos em todo o mundo, 'Como fazer amigos e influenciar pessoas' é considerado um dos principais livros no genêro, influenciando com ótimos conceitos a todos no âmbito pessoal e professional" http://www.saraiva.com.br/como-fazer-amigos-e-influenciar-pessoas-4053082. html. Acesso em 17 de fevereiro de 2017.

8. Trata-se de um texto de $A$ sombra das raparigas em flor, vol2, traduçâo de Mário Quintana. 